\title{
Eco-friendly fishing methods and techniques practiced in the northern hills zone of Chhattisgarh state, India
}

\author{
P. Mooventhan ${ }^{1 *}$, K. S. Kadian ${ }^{2}$, R. Senthil Kumar ${ }^{2}$, C. Karpagam ${ }^{3}$, B. K. Choudhary ${ }^{1}$ \\ ${ }^{1}$ ICAR- National Institute of Biotic Stress Management, Raipur- 493 225, (Chhattisgarh), INDIA \\ ${ }^{2}$ ICAR-National Dairy Research Institute, Karnal - 132 001, (Haryana), INDIA \\ ${ }^{3}$ ICAR- CICR, Regional Station, Coimbatore - 641 003, (Tamil Nadu), INDIA \\ *Corresponding author. E-mail: agriventhan@yahoo.co.in
}

Received: September 22, 2015; Revised received: March 17, 2016; Accepted: June 1, 2016

\begin{abstract}
Indian forests have the potential to safeguard the livelihood of forest dwelling people, particularly tribal people, who are among the most disadvantaged groups in our society. Tribal people generally depend on forests for their cultural, spiritual, and to varying degree of economic needs. Fishing is one of the important livelihood activities of the tribal community since the time immortal. Fishing provides the source of livelihood as well as nutritional security to the tribal family significantly. An explorative study was conducted in participatory mode to explore the eco -friendly fishing methods. Totally, 300 respondents were selected for this study. The data was documented with the help of participatory observation, focused group discussions with triangulation procedures. In the paper, eco-friendly fishing methods such as Kumani, Pahata, Mora, Donga, Pelna, Choppa, Mora, Gulel, Bhawarjal, Ditori, Beetaah, Chiwaar, Baahla and Jholna and their working procedures are discussed. Jholna used to catch small and medium sized fishes upto $5-7 \mathrm{~kg} /$ day. The production cost of this choppa is less than Rs. 250 and it is used to catch small sized fishes up to $1.5-2.5 \mathrm{~kg} / \mathrm{day}$. Kumani is used to catch small sized fishes and crabs upto $1-2 \mathrm{~kg} / \mathrm{day}$. The making cost of Pelna is around Rs. 650 and it is used to catch fishes upto 6-7 kg/day. The construction cost of Pahata gear is around Rs. 2000 and It is used to catch medium to big sized fishes upto $8-10 \mathrm{~kg} /$ day.
\end{abstract}

Keywords: Eco-friendly fishing methods, Gond tribe, Kumani, and Pahata

\section{INTRODUCTION}

India is a vast and diverse country, which is also a home for over one-fourth of world's absolute poor. Among the social groups in India, scheduled tribes have the highest proportion of the poor. While they account for only 8 percent of the total population, they comprise 40 percent of the displaced population. The population of Chhattisgarh is notable for the high proportion of Scheduled Tribes which constitute 30.6 percent of the total state populace (FAO, 1997 and TIN, 2013). The tribes of Chhattisgarh are unique race with strong traditional knowledge base in agriculture and allied subjects (CTDS, 2013). Chhattisgarh, the $26^{\text {th }}$ State of India, was carved out of Madhya Pradesh on November 1, 2000. Located in central India it covers an area of 1,35,133 sq $\mathrm{km}$. Chhattisgarh is bordered with Bihar, Jharkhand and Uttar Pradesh in the north, Andhra Pradesh in the south, Orissa in the east and Madhya Pradesh in the west (PIB, 2001). Chhattisgarh has endowed with varied water resources like total fresh water resources is 1.47 lakh ha of which reservoir is 0.84 lakh ha, tanks and ponds is 0.63 lakh ha, and rivers and canals constitutes about $3573 \mathrm{~km}$ which could be exploited economically, and sustainably more to provide livelihoods security as well as economic security to the tribal community (DFC, 2014).

Fish production in open waters is common practice in many Asian countries, has not yet gain recognition among the fishers of eastern states of India. Fisheries sector could play key role to utilize this opportunity to generate substantial revenue through sustainable exploitation of this prime natural resource (Pankaj et al., 2015). The vast and varied inland water resources constitute important fishery resources in the State of Chhattisgarh. In recent years the fish production from these resources has increased considerably, but less improvement has happened in the traditional fisher folk economic conditions. These concerns are more important in the context of rising environmental degradation, emerging new economic order (Gurumayaun and Choudhury, 2009). Inland water resources harbour the original germplasm of one of the richest and most diversified fauna. (Amaranth and Apurba, 2015). These resources provide full time vocation of about 28768 registered society members covering 1.85 lakh of fishers and yield about 3.12 lakhs tone of fish. Chhattisgarh is one of the potential producers of inland fishes in the country and fisheries sector plays an important role in providing nutritional security and source of livelihood to rural fishers, it also engages rural population in supporting activities such as mar- 
keting, retailing, vending, transportation etc., (DFC, 2014). However, the sector remains unorganized because of scattered nature of activities. Chhattisgarh state is playing an important role by generating selfemployment through fisheries in rural areas which in turn provides nutritious food to rural folks. Fisheries business has generated an employment potential for about 1.85 lakh persons, most of them belong to tribal community representing the weaker section of the society. There is a network of four rivers namely Mahanadi, Godawari, Ganga and Narmada which covers a length of about $3573 \mathrm{Kms}$. in the state and in this network, 31 large, small rivers and tributaries flow from East to West offer themselves with vast water area for fishing and fishery development activities to the tribal community (DFC, 2014). Fishing is free in rivers and most of the fishing in river is done by the local tribal community with their own indigenous methods using traditional ingenious gears and crafts. The main objectives of the study were to make complete documentation of indigenous fishing methods and techniques with its working procedure followed by the tribal community.

\section{MATERIALS AND METHODS}

Study area: Geographically, Chhattisgarh state lies between the latitude of $17^{\circ} 47^{\prime}$ and $24^{\circ} 06^{\prime}$ North and longitude of $80^{\circ} 15^{\prime}$ and $84^{\circ} 24^{\prime}$ East. The central part of the state lies in the fertile upper basin of the Mahanadi river and its tributaries. The Mahanadi is the chief river of the state. The other main rivers are Hasdo (a tributary of Mahanadi), Rihand, Indravati, Jonk, Arpa and Shivnath. The northern and southern parts of the state are hilly, while the central part is a fertile plain. Deciduous forests of the eastern highlands forests cover roughly $44 \%$ of the state (Forest Survey of India, 2009). The climate of Chhattisgarh is tropical. It is hot and humid because of its proximity to the Tropic of Cancer and its dependence on the monsoons for rains. The monsoon season commence from late June to October gives the opportunity to tribal people in fishing activities. Chhattisgarh receives an average annual rainfall of $1200 \mathrm{~mm}$ to $1600 \mathrm{~mm}$ approximately with an average annual rain fall of around $1400 \mathrm{~mm}$. The temperature varies between 30 and $47^{\circ} \mathrm{C}$ (86 and $117^{\circ} \mathrm{F}$ ) in summer and between 5 and $25^{\circ} \mathrm{C}$ (41 and $77^{\circ} \mathrm{F}$ ) during winter. However, extremes in temperature can be obsevered with scales falling to less than $0^{\circ}$ $\mathrm{C}$ to $49^{\circ} \mathrm{C}$. There are three agro climatic zones comprising of northern hills, central plains zone and Bastar plateau zone and the northern hills zone were selected for this study. This study was conducted in four districts viz., Balrampur, Surajpur, Surguja, and Jashpur of Chhattisgarh state. These four districts were purposely selected because; these districts have the highest tribal populace in the Northern hills zone. Indigenous fishing methods were documented using a Participatory Rural Appraisal (PRA) tools, participatory observation, indi- rect observation, on-site documentation, key informant survey and focused group discussions. Descriptive statistics are used to describe the basic features of the data in the study and it provides simple summaries. about the sample and the measures.

\section{RESULT AND DISCUSSION}

In the present study tribes of Chhattisgarh have unique frame of traditional knowledge in river and pond fishing methods. Their fishing methods are distinctive according to working procedure, construction, size, seasonal use, raw material and execution process. The different methods, procedure, gears and crafts used in the indigenous fishing methods in lentic and lotic water bodies were observed during the study.

Jholna or Charguduva or Hathari: It is one of the common fishing devices practiced by the tribal fishing community in pond as well as river, where the water flow is less or in stagnated condition. This structure is made up of three young hollow bamboo (Dendrocalamus strictus) poles, nylon or cotton mesh and coconut or jute rope. Two bamboo poles were tied criss-cross with the help of coconut or jute rope and each end attached with the nylon mesh, further the whole structure attached with another long pole and rope which have the access to fisherman as shown in the (Fig. 1). The top portion of the Jholna is always open which have the concave structure. While fishing, the whole structure is immersed into the water and the bait (Busa ka koda - Rice and wheat bran mix) sprayed over the concave portion into the water (Fig. 2). After bait spray, the fisherman holds the Jholna in idle position for 5-10 minutes, allowing fishes to feed the bait. Once the movements of fishes are observed in the Jholna, the fisherman brings out the Jholna from the water. Then the fisherman collects the fishes from concave portion of the Jholna. The making cost of this indigenous gear is less than Rs. 600 and it is used to catch small and medium sized fishes upto $5-7 \mathrm{~kg} / \mathrm{day}$.

Choppa: Choppa is the user friendly fishing tool with the shape of triangular prismatic cone structure made up of fine bamboo splints with two outlets starting with wider (40 to $70 \mathrm{cms}$ ) to narrow (20 to $25 \mathrm{cms}$ ) opening as shown in the (Fig. 3). Bamboo splints are tied together with the help of strong thread often iron wires also used to make the structure. Choppa is usually used in the running streams as well as standing water where the depth of the water is low because its height is around 80 to $100 \mathrm{cms}$ only. Once the fishes are noticed on the shallow surface of the water, the Choppa is placed upside down into the water and the trapped fishes are collected by inserting their hand through the small inlet entry. It is used to catch very small sized fishes and crabs. The making cost of this choppa is less than Rs. 250 and it is used to catch small sized fishes up to $1.5-2.5 \mathrm{~kg} /$ day.

Kumani: Kumani is small in size and has the similar shape as Choppa, but interestingly it has the special 
trapping mechanism at its lower end as shown in (Fig. 4). This mechanism allows the fishes and shell fishes to enter inside and after entering the filter chamber will not allow the fishes to escape from the Kumani. The trapped fishes are collected by hand through the small opening and closing system which is tied in the bottom. It is used to catch very small sized fishes in the running water. The making cost of kumani is less than Rs. 200 and it is used to catch small sized fishes and crabs upto $1-2 \mathrm{~kg} / \mathrm{day}$.

Bada and Chota Pelna: Pelna is triangular bamboo frame with weaved nylon net is tied with the triangular

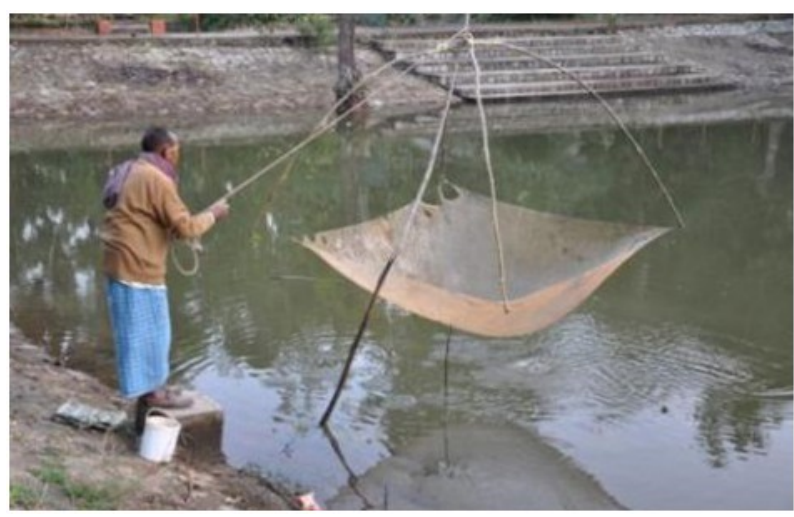

Fig. 1. Jholna or Charguduva placed in the pond.
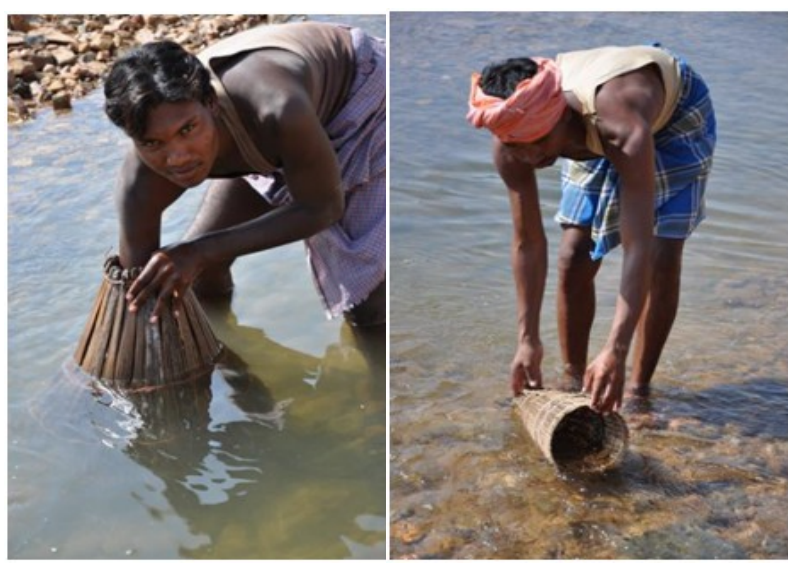

Fig. 3. Choppa

Fig. 4. Kumani

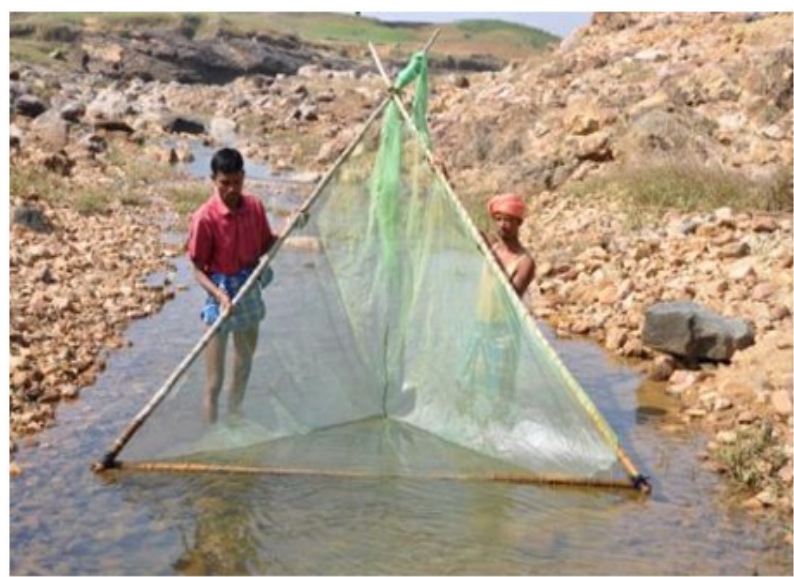

Fig. 6. Tribal fisherman with Bada pelna in river stream. frame, one arm of triangular frame is having long handle of bamboo for holding the Pelna upright. It is operated under waist height deep water, they move forward keeping Pelna upright from the bottom of ponds or rivers as shown in (Fig.5 and 6) (Pradhan et al., 2011). The size of the Pelna is decided based on the fishing place where the water flow and depth varies. It is used to catch medium to big sized fishes in the river as well as pond. The making cost of this indigenous gear is around Rs. 650 and it is used to catch fishes upto 6$7 \mathrm{~kg} /$ day.

Pahata: It is relatively one of the big fishing structures

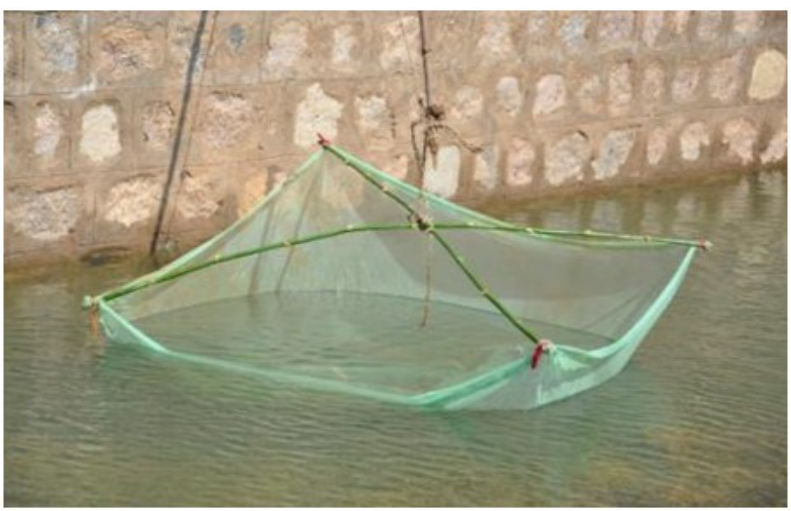

Fig. 2. Modified Jholna while fishing from elevation.

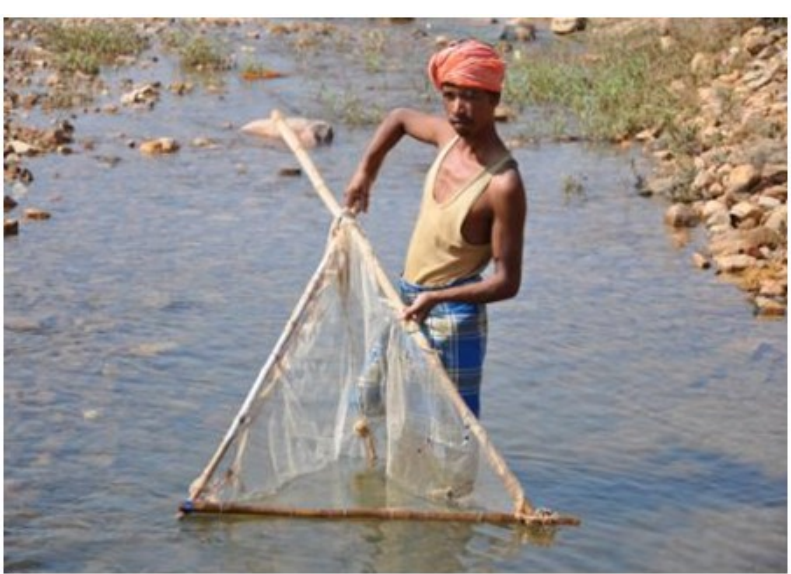

Fig. 5. Tribal fisherman with Chota pelna.

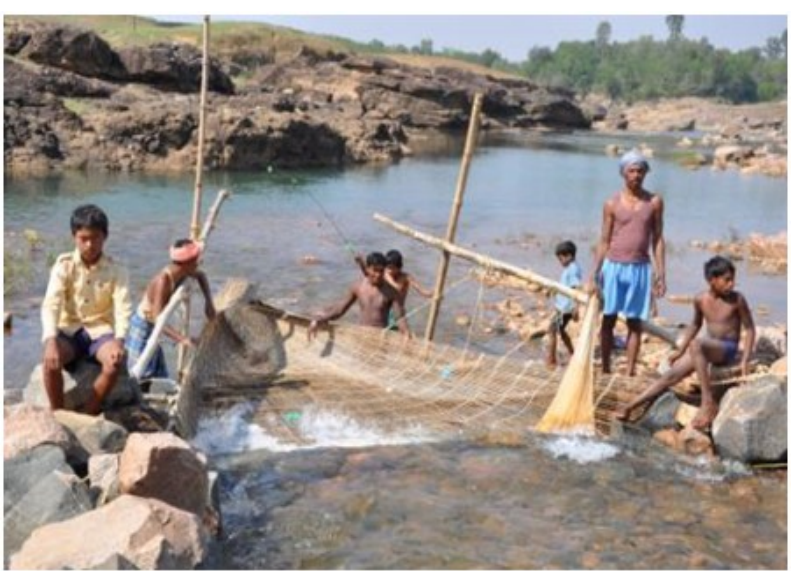

Fig. 7. Tribal fisherman in action with Pahata. 


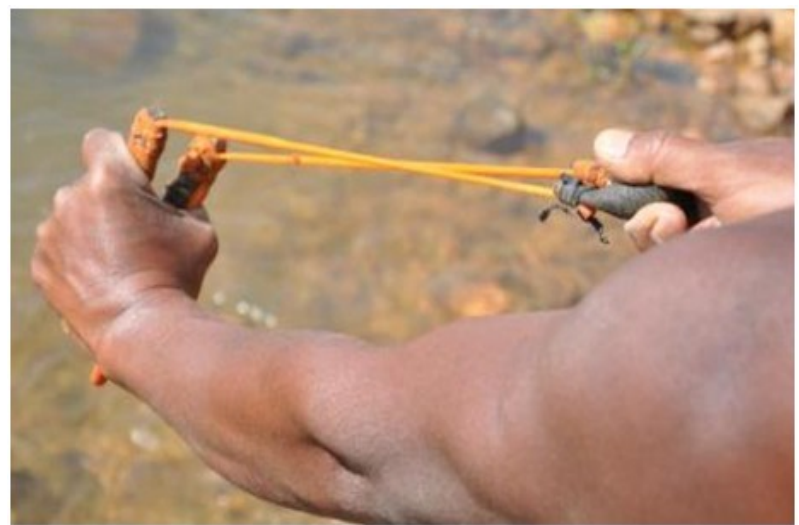

Fig. 8. Gulel in action for fishing.

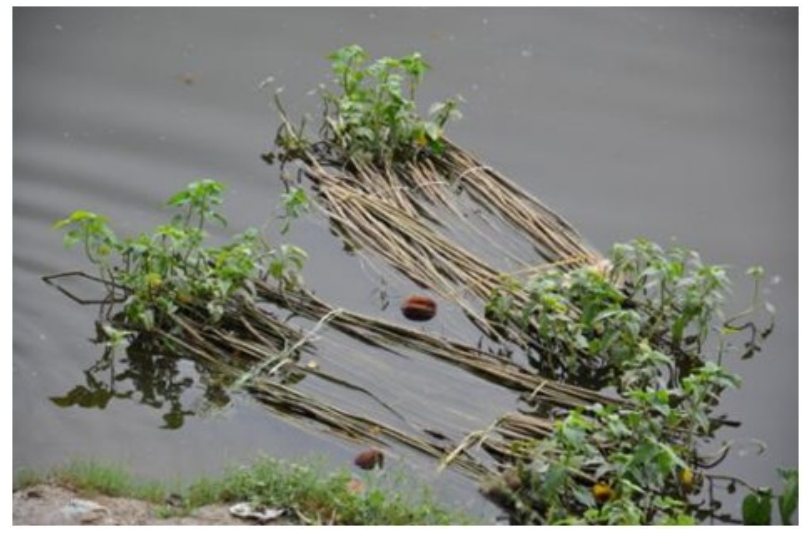

Fig. 10. Nav or Dong - Live fishing boat.

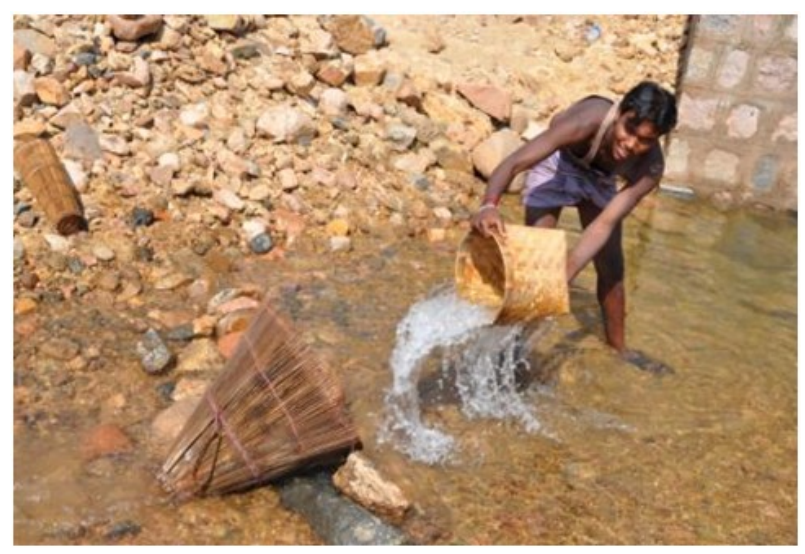

Fig. 12. Fishing with Mora and Choppa.

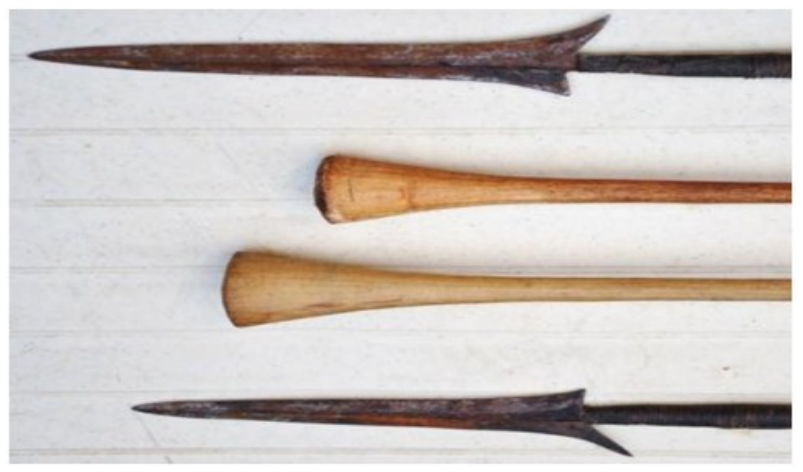

Fig. 14. Chiwaar and Beetaah.

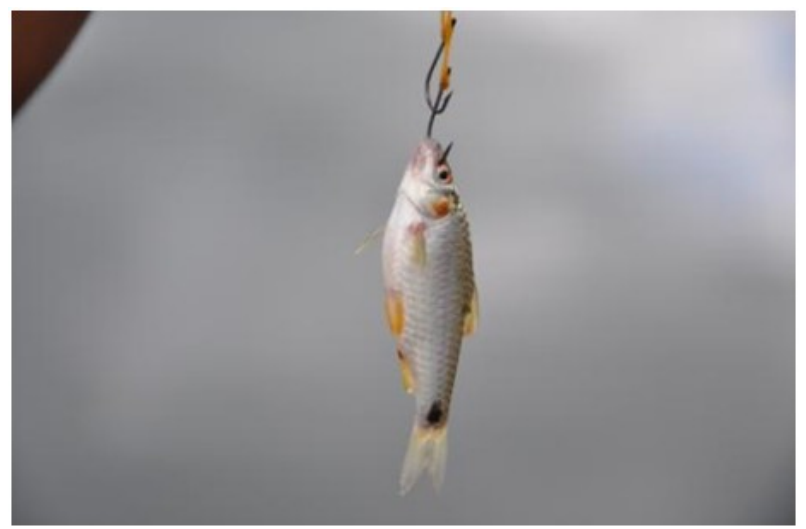

Fig. 9. Hook and catch in Dong bansi

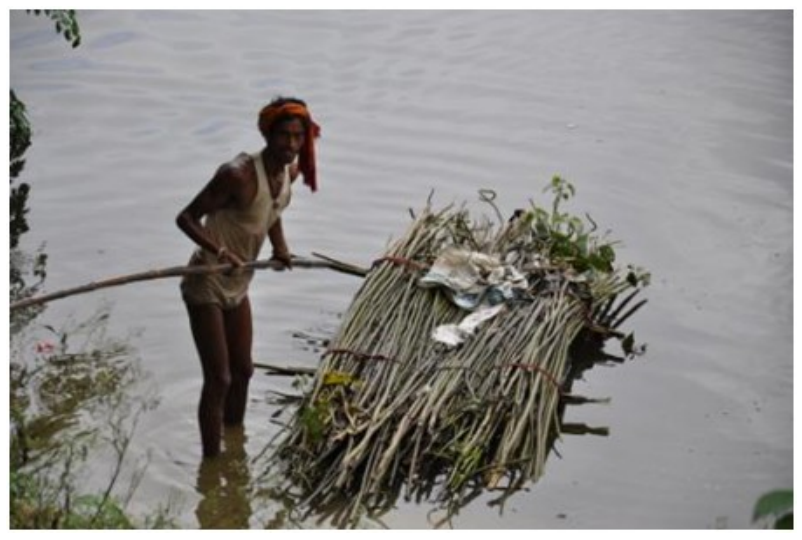

Fig. 11. Nav or Dong used by fisherman.

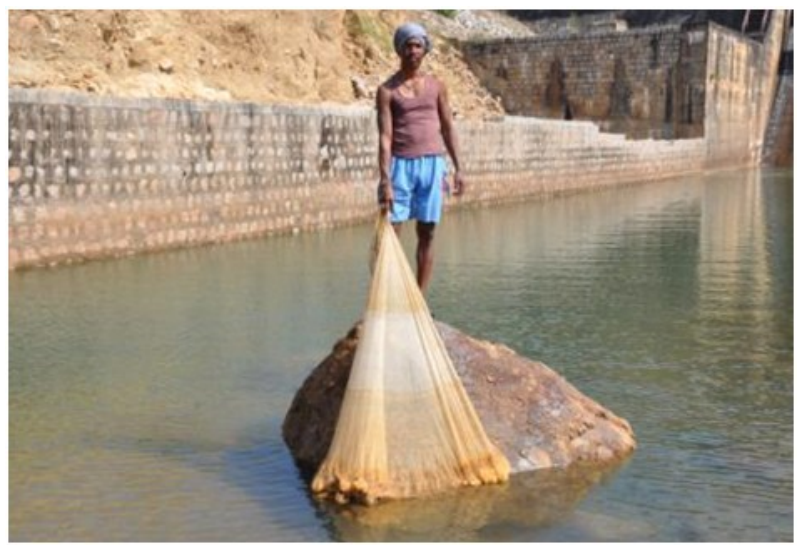

Fig. 13. Tribal fisherman with handmade Bhawarjal.

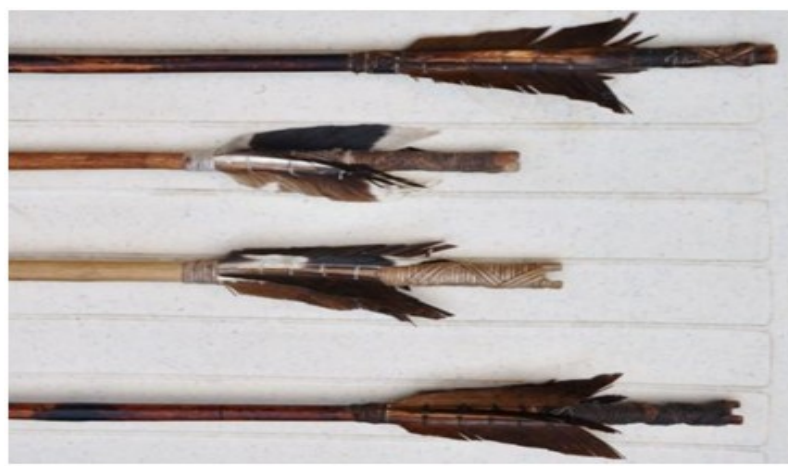

Fig. 15. Arrow nock, feather fletching, sinew and shaft. 
used by the tribal fisherman of Chhattisgarh. This huge structure is placed in between the river stream as shown in the and both the side of the Pahata supported by the strong bamboo poles and stones. Pahata's both the sides connected by large sized mat which is a flexible structure made up of fine bamboo splints (Fig.7). The flexible mat has wider opening at the beginning which is gradually narrowed at the end where fisherman collects the trapped fish. Pahata is the permanent structure where the continuous water flow is exists. It is used to catch medium to big sized fishes in shorter time. The making cost of pahata gear is around Rs. 2000 and It is used to catch medium to big sized fishes upto $8-10 \mathrm{~kg} /$ day.

Gulel: Gulel is one of the handy fish hunting devices used by the tribal fisherman. Gulel is commonly known as Sling and karban and it is made with the help of strong wooden fork, rubber strip and leather piece. Here, two independent rubber strips are tied in both the end of the wooden fork and another two ends of the rubber strips connected by the leather piece as shown in the (Fig. 8). Pebbles stones are kept in the leather piece of the rubber string which is then drawn back, when the rubber string is released the potential energy of the flexed stick is transformed into the velocity of the stone which hits the fish. The making cost of this indigenous gear is less than Rs. 100 and it is used to catch medium sized fishes upto $1 \mathrm{~kg} /$ day.

Dong bansi: Dong bansi is a handcrafted fishing device with slender, long, flexible length of bamboo sticks used to catch the fish. At its simplest, Dong bansi is a bamboo stick with a line ending in a hook and the hook connected with the bamboo stick through a strong nylon or cotton thread as shown in the (Fig. 9). In between the hook and bamboo stick, a lightweight material such as Jowar and Bajra stem were tied in the thread used to indicate the fish activities, while the fish feed the bait. Once the fish approached the bait, which is connected to hook, the floating indicator will immerse into the water, and then the fisherman will make sudden pull action and bring out the fish. The making cost of this indigenous gear is less than Rs. 200 and it is used to catch small and medium sized fishes upto $2-3 \mathrm{~kg} /$ day.

Nav or Donga: It is a live fishing boat made up of Basrem (Ipomoea carnea) stem; it is also known as pink morning glory. This flowering plant considered as a one of the aquatic weed which is available in the river banks and ponds in plenty. The stem of Basrem are light in weight and have the capability to float in water, because of this advantage tribal fisherman using this stem to make Nav or Donga as shown in the (Fig.10 and 11). Underneath of this structure is supported by the motor vehicle's inner tubes to facilitate better ride for fishing in the ponds. The making cost of this indigenous gear is less than Rs. 100 as it is made up of freely available aquatic weed, and it is rarely used to catch small sized fishes.
Mora: Mora is a medium sized rectangular structured device like basket with wide opening and which is made up of long, wide and individual bamboo splints. Generally, Mora is a supporting device in fishing used to drain the water into the fishing device such as Kumani. The making cost of this gear is less than Rs. 100 and it is used to catch small sized fishes (Fig.12).

Ditori: It is a miniature box like apparatus which have three parts namely small inlet, lid to close and handle to carry. Ditori made up of bamboo splint or palm leaves to keep the fishes alive for long time in water; because Ditori has its own advantage which allows the water exchange by inside and outside through the tiny perforations (Fig.12). The making cost of this gear is less than Rs. 150 and it is used to hold small and medium sized fishes.

Bhawarjal: Bhawarjal is a fishing devices made up of fibre, woven in a grid-like structure. Fishing nets are usually meshes formed by knotting a moderately thin thread as it is been used in phenka jal practiced in Eastern India (Ramkrishna and Sudip Barat, 2004). These handmade nets were woven using cotton threads, but in recent days tribal people often using artificial polyamides like nylon to make strong fishing nets as shown in the (Fig. 13). The mesh size and radius of the bhawarjal jal varies from $0.5-2.0 \mathrm{~cm}$ and 1.0-2.0 $\mathrm{m}$ respectively depending upon the type of water bodies it is operated upon. The size of the Bhawarjal varies based on the utility and it is used to catch medium to big fishes. The making cost of this indigenous gear is less than Rs. 2000 and it is used to catch fishes upto $8-10 \mathrm{~kg} / \mathrm{day}$.

Chiwaar: Chiwaar is one of the most primitive fishing gears used traditionally by the tribal community (Priya Ranjan et al., 2010). Chiwaar is a dry solid bamboo sticks selected as around $100 \mathrm{cms}$ size in length. The size of the Chiwaar varies based on the size of the bow. The arrows were then carved to the required shape and sometimes straightened using fire as well as high weight material placed on the arrow shaft. Notches were carved at either end of the arrows to accommodate the arrowhead, which is made up of sharp iron point (Fig. 14). The arrow flight made up of feathers fletching with arrow nock, and sinew and the feathers were used to give arrows their spin during flight. The tribal fisherman used to stand on the elevation or in the knee level water of ponds or rivers to hunt the swimming fishes on the surface of the water. After the fish observed, immediately the string is released and the arrow hits the fish. The making cost of this indigenous gear is less than Rs. 200 and it is used to catch medium and big sized fishes.

Beetaah: Beetaah is similar to Chiwaar, in shape and method of use, only the difference is arrowhead. In Beetaah, arrows shift end with arrowhead which is blend in shape without any iron point and the arrow flight made up of feathers fletching with arrow nock, and sinew as shown in the (Fig. 15). Beetaah is 
carved to the required shape made up of locally available woody plant called Baahs. Beetaah is mostly used to hunt the birds but often used to hunt the fish also. The making cost of this indigenous gear is less than Rs. 100.

Baahla: Baahla is a handy oldest fishing tool commonly known as spear made up of strong bamboo pole ending with sharp iron point. The spearhead has the serrated tip which will not allow the fish to escape. The tribal fisherman used to stand in the knee level water of ponds or rivers to hunt the swimming fishes on the surface of the water. The making cost of this indigenous gear is less than Rs. 200 and it is used to catch medium to big sized fishes.

\section{Conclusion}

The present study concluded that eco-friendly indigenous knowledge is primarily inherited from the ancestors through generations. Such knowledge stands as the main source of utilization and management of natural resources. It is not only a self centred knowledge but a collecting knowledge, the collection of phenomena and experiences. This traditional knowledge and practice can play a great role in enhancing our understanding for devising fishing techniques.. So, in this respect priority should be given to the indigenous traditional knowledge. The local communities, being inhabitant in and around the water bodies largely depend upon the natural wealth of their habitat not only for their basic need but also for amenities of life. So, traditional knowledge should be conserved as a part of living cultural ecological system, helping to maintain a sense of pride in local cultural knowledge and practices and reinforcing link between communities and environment, so essential for conservation.

\section{ACKNOWLEDGEMENTS}

The authors express their sincere thanks to the peoples of tribal communities of Balrampur, Surajpur, Surguja, and Jashpur of Chhattisgarh state and the key informants Mr.Giri, Mr. Krishna, Mr.Shivnath, Mr.Bhahadur and Mr. Parsan for their valuable contribution and effective participation in the documentation process.

\section{REFERENCES}

Amaranth, S. and Apurba, R.G. (2015). Influence of hardness and alkalinity on breeding potentiality of Indian major carps. The Ecoscan, 9 (1 and 2) : 43-47, 2015.

CTDS, (2013). Project on : Chhattisgarh Tribal Development programme. Chhattisgarh Tribal Development Society, IFAD

DFC, (2014). Important Activities \& Statistics of Chhattisgarh State's Fisheries. Department of Fisheries Chhattisgarh.

FAO, (2007). India: Bihar-Madhya Pradesh Tribal Development Programme. Food and Agricultural organisation, Rome, Italy.

Forest Survey of India, (2009). India State of Forest Report. Ministry of Environment \& Forests, Govt. of India.

Gurumayaun and Choudhury, M. (2009). Fishing methods in rivers of Northeast of India. Indian J. Traditional Knowledge, 8 (2): 237-241.

Pankaj P., Hassan, M.A. and Mishra, A.P. (2015). Growth performance of carp fries reared in pen in a floodplain wetland of north Bihar, India. The Ecoscan, 9 (1 and 2): 137-141, 2015

PIB, (2001). Chhattisgarh : The $26^{\text {th }}$ state of India. Government of India. Press Information Bureau, India.

Pradhan A., Nag, S.K. and Patil, S.K. (2011). Traditional fishing techniques of tribes in Bastar region of Chhattisgarh. Indian J Traditional Knowledge, 10 (2): 386-387.

Priya Ranjan, M., Rabindra, K. and Mahapatra (2010). Documenting Indigenous Traditional Knowledge in Odisha. Orissa Review, (5-6): 99-103.

Ramkrishna, D. and Sudip, B. (2004). Fishing gears operated in lentic and lotic water bodies of Cooch Behar districts, West Bengal, India. Indian J Traditional Knowledge, 13 (3): 619-625.

TIN, (2013). Tribal Profile at a Glance. http: //tribal. nic. in/ Write ReadData/archive Doc/ 201410170113319773837 ST Profileata Glance. pdf. Accessed $22^{\text {nd }}$ February 2016. 